\title{
o Terceiro Setor no Turismo: o caso da Câmara de Turismo de Rio Grande do Sul (Brasil)
}

\author{
Third Sector in Tourism Business: a case study on the Chamber of Tourism of Rio Grande \\ do Sul (Brazil)
}

Luis Gustavo Patrucco ${ }^{1}$

Margarita Barretto ${ }^{2}$

\begin{abstract}
Resumo
Este artigo resume uma pesquisa descritiva orientada a registrar o surgimento, a consolidação e o aporte da Câmara de Turismo de Rio Grande do Sul ao desenvolvimento do turismo no Estado e os desafios que enfrentou como pioneira das organizações do terceiro setor no turismo no Brasil. Trata-se de uma pesquisa documental, que utilizou também procedimentos de história oral e da observação participante e que está fundamentada nas novas teorias sobre o papel do Estado e da iniciativa privada no planejamento e gestão do turismo. Ao mesmo tempo tem a intenção de estimular a reflexão sobre a importância que organizações do terceiro setor podem ter para o desenvolvimento do turismo em outros estados por ser um modelo amplamente utilizado por outros países da América Latina.

Palavras-chave: turismo; planejamento de turismo; políticas públicas; terceiro setor; Câmara de Turismo do Rio Grande do Sul.
\end{abstract}

\begin{abstract}
This article summarizes a descriptive survey aimed to record the emergence, consolidation and the contribution of the Chamber of Tourism of Rio Grande do Sul to the development of tourism in the State and the challenges he faced as a pioneer of the third sector organizations in tourism in Brazil. This is a documentary research, which also utilized procedures of oral history and participant observation and which is based on new theories about the role of government and private initiative in tourism's planning and managing. At the same time is intended to stimulate reflection on the importance of nonprofit organizations can have on tourism development in other states because it is a model widely used by other countries in Latin America.

Keywords: tourism; tourism planning; public policies; third sector; Tourism Chamber of Rio Grande do Sul, Brazil.

1 Arquiteto (Universidade Nacional de Buenos Aires). Mestre em Turismo (UCS). Professor dos cursos de Hotelaria, Marketing, Administração e Desenvolvimento de Sistemas da FATEC -SENAC-RS. Professor do ILAM Costa Rica.E-mail: lpatrucco@gmail.com.

2 Doutora em Educação pela Unicamp. Professora da FURB-Fundação Universidade Regional de Blumenau e da UFSC- Universidade Federal de Santa Catarina. E-mail: barretto.margarita@gmail.com.
\end{abstract}




\section{Introdução}

Estudando a trajetória histórica da atividade turística, pode-se observar em vários países do mundo, uma progressiva mudança das responsabilidades assumidas pelos setores público, privado e a sociedade mais ampla, para com o seu desenvolvimento.

Na década de 60, na maioria dos países, os governos assumiam o papel de pioneiros nos investimentos da atividade turística, principalmente nas questões de infra-estrutura básica. Em muitos casos também se encarregavam do seu gerenciamento, ocupando-se de atividades como hotelaria, operadoras turísticas e transportadoras. Como exemplo pode-se citar a Espanha que implantou, a partir de 1928 uma rede de paradores, alojamentos construídos especialmente ou instalados em lugares históricos, tais como castelos, palácios e conventos (Ocho décadas de historia, disponível em http://www.paradores.es/es/portal.do?IDM=121\&NM=3). (Cayón Costa, 2007, p. 72)

Atualmente a maioria dos governos está abrindo mão de seu papel principal nos interesses e necessidades referentes à infra-estrutura e serviços turísticos, ficando com a responsabilidade da promoção institucional do destino, a dos assuntos relativos à legislação e regulamentação das atividades relacionadas ao setor.

No que se refere ao turismo, percebeu-se que a competitividade de uma destinação turística exige que o setor público, o setor privado e a sociedade assumam uma atitude de cooperação para trabalhar de forma conjunta focalizando: a melhoria da atratividade do destino, a melhoria da eficácia do marketing, a melhoria da produtividade, o controle dos limites ambientais e culturais e a melhoria da gestão deste complexo e diverso fenômeno social.

Na Nova Zelândia, por exemplo, há trinta e duas instituições -públicas, privadas e do terceiro setor- envolvidas no planejamento do turismo (HALL, 2000, p. 145-151). Na Inglaterra o turismo é gerenciado pelo National Trust, organização do terceiro setor, que gerencia também o patrimônio cultural direcionado ao turismo. (TYLER, 2001)

No Brasil, de acordo com Flores (1993), o estado do Rio Grande do Sul é pioneiro no desenvolvimento do turismo com a promulgação da Lei 997, em 1950, a autora qualifica como "fa- 
to inédito no Brasill” a inclusão, por parte do estado, de dotação orçamentária específica para o Serviço Estadual de Turismo no quadriênio 1959-1962 . Esse pioneirismo também se manifestou em ações da iniciativa privada como por exemplo o Touring Club, que, tendo sido fundado no Rio de Janeiro em 1923 chegou ao RS em 1935, desenvolvendo intensas atividades. Foi também o primeiro estado a criar uma organização do terceiro setor voltada aos interesses da atividade turística, em 1989; a Câmara de Turismo foco de estudo da dissertação de Mestrado que da origem ao presente artigo (PATRUCCO, 2006), cujo objetivo foi registrar a trajetória da câmara e aportar material bibliográfico que auxilie na compreensão do papel das organizações do Terceiro Setor no desenvolvimento do turismo.

\section{Metodologia}

Trata-se, de um estudo de caso, com pesquisa bibliográfica, pesquisa documental e entrevistas em profundidade. Esta pesquisa é de corte qualitativo onde se considera que existe uma relação indissociável entre o ambiente objetivo e a subjetividade do pesquisador. Os dados não podem ser expressados em números, e não são analisados por meio de instrumentos estatísticos, pois a mensuração e a quantificação não fazem parte deste tipo de pesquisa (RICHARDSON, 2007). Sendo um estudo de caso, tampouco tem pretensão de ter caráter universalisante (LAVILLE e DIONNE, 1997; MARCONI e LAKATOS, 1982) mas sim de realizar um estudo em profundidade.

Desde que a dissertação mencionada foi o primeiro documento a sistematizar a história da Câmara, encontrar a documentação que registra sua história e trajetória foi uma tarefa difícil já que não existe um padrão administrativo de registro e arquivo das diversas atividades desenvolvidas desde sua fundação.

Por esta razão foi necessário realizar entrevistas, para reconstruir os fatos mediante a história oral, técnica que permite registrar a memória individual e coletiva a respeito dos mesmos e que pode ser utilizada tanto para comparar a percepção das pessoas sobre fatos do passado e compará-los com a história oficial quanto para reconstruir fatos sobre os quais não há história escrita (THOMPSON, 1978). A limitação da fonte oral é que fornece dados de uma forma 
genérica, sem permitir, por exemplo, especificar quantos eventos a Câmara organizou ou que porcentagem de aumento de receita ou de divisas a ação da Câmara propiciou.

Cabe mencionar que, também foi grande a dificuldade de encontrar referencias bibliográficas sobre as entidades do terceiro setor relacionadas ao planejamento do turismo de terceiro nível (BARRETTO, 2005), tanto em idioma português como em outros idiomas. A pesar de haver literatura tratando de ONGs e turismo (DREHER e GORNI, 2010, FREIRE-MEDEIROS 2009, RAVINOVICI e FERREIRA, 2008, MATTOS e DRUMMOND, 2005, DOIRON 2001, WÖHLKE, 2005) o que foi achado após exaustiva pesquisa nas bases de dados nacionais e internacionais refere-se a turismo alternativo (ecoturismo e comunitário, mormente rural), ou a ambientalistas que procuram um turismo mais brando. Foi difícil achar antecedentes sobre o planejamento do turismo em sentido amplo em nível regional ou estadual por parte de organizações do o terceiro setor. Isto confirma a afirmação de Pereira (2005) de que no Brasil o Estado tem-se preocupado mais com a promoção do turismo do que as organizações do terceiro setor, mais preocupadas com os problemas sociais. Uma pesquisa que guarda uma certa semelhança com a presente é a de Gorni, Dreher e Machado (2009), que registra a trajetória da ONG Balneário Camboriu "Com Vida Convention and Visitors Bureau”, fundada em 2003 que atua na área de promoção de eventos mas não trata de planejamento em nível estadual, como é o caso do objeto do presente estudo.

Cabe destacar ainda que data apenas de 1997 a criação de uma rede de informações para sistematizar os dados sobre o terceiro setor no Brasil, o que foi feito por iniciativa do programa Comunidade Solidária, desde que até então não existiam “informações confiáveis", conforme afirmação da então Primeira Dama (CARDOSO, 1997, p. 11)

Nesta pesquisa, o procedimento para obtenção de dados foi a observação participante. Esta metodologia consiste na observação do fenômeno estudado com a participação ativa do observador na comunidade ou situação determinada e onde o observador assume seu papel como membro do grupo. (LAVILLE e DIONNE, 1999; MARCONI e LAKATOS, 1982). Richardson (1989, p.215) aponta que na observação participante "o observador não é apenas o espectador do fato que está sendo estudado, ele se coloca na posição e ao nível dos outros elemen- 
tos humanos que compõem o fenômeno a ser observado". No caso deste trabalho, o pesquisador era diretor de planejamento da Câmara.

Para selecionar os participantes da investigação, foram considerados os estudos de Minayo (1992, p. 100), que define as principais características da amostragem na investigação qualitativa, apontando como critérios básicos a) Privilegiar os sujeitos sociais que apresentem os atributos enfocados na investigação; b) Estabelecer um número suficiente de participantes para possibilitar reincidência de informações;c) Que o conjunto dos participantes possa ser diversificado, a fim de possibilitar a apreensão de semelhanças e diferenças.

Em consonância com Minayo (1992, p. 102)

Numa busca qualitativa, preocupamo-nos menos com a generalização e mais com o aprofundamento e abrangência da compreensão, seja de um grupo social, de uma organização ou de uma instituição.

O primeiro procedimento foi a coleta de documentos para a análise. Em seguida foi o de listar os nomes dos ex-presidentes da Câmara, os nomes de alguns presidentes de entidades afiliadas a Câmara de Turismo e os nomes de pessoas ligadas a cargos públicos que tinham ou tiveram relação com a Câmara de Turismo. De posse dessas informações foi então realizada a seleção dos participantes, que foram divididos por categorias, a saber, diretores da entidade, membros da comunidade acadêmica e representantes do poder público. As perguntas norteadoras foram: 1) Que razões motivaram a criação da Câmara?; 2) Quais os modelos de referência nos quais os fundadores se basearam para a criação da Câmara?; 3) Quais os projetos de turismo que tiveram a participação da Câmara?; 4) Como é o relacionamento entre a Câmara e as instituições associadas?; 5) Como é o relacionamento entre a Câmara e o poder público?

Foram entrevistadas pessoas que exerceram ou exerciam a presidência da Câmara de Turismo; pessoas que exerciam ou exerceram a presidência de entidades participantes da Câmara de Turismo e pessoas que possuíam cargos em órgãos públicos que se relacionavam com a Câmara de Turismo. 
Alguns dos entrevistados tinham o duplo papel de ser representantes de um dos grupos e ao mesmo tempo ser parte dos "fundadores"da Câmara.

\section{A Atividade Turística}

A Câmara é por excelência uma instância de planejamento da atividade turística. Assim, é preciso, para entender seu papel e importância, entender que o turismo é um fenômeno social polifacético e relacional cujo planejamento tem um alto grau de complexidade visto todos os agentes envolvidos: os atores sociais, os agentes naturais, a cultura e a infra-estrutura, as relações políticas e outras. Portanto, a seguir, discorrer-se-á sobre turismo e planejamento.

O turismo, quando abordado sob diferentes olhares, aparece como uma atividade com múltiplas relações. A atividade turística tem sido objeto de diversas definições provenientes de distintas correntes de pensamento, que não serão detalhadas neste artigo.

Serão, sim, arroladas as diferentes formas em que o turismo enquanto sistema tem sido representado, assim como os modelos de planejamento elaborados, desde que nestes modelos de planejamento pode-se ver a necessidade de diálogo entre os diversos integrantes dos sistemas.

Baptista (1987, p. 59) elabora uma representação sistêmica na qual o turismo se encontra dentro de um "meio envolvente", onde se insere o social,, o econômico, o político e o internacional (que faz supor que os outros meios se referem apenas ao nacional). Dentro da esfera do turismo ele coloca o elemento humano (turista) o elemento físico, que para ele seria a região de origem, o elemento turístico (região turística) e o elemento econômico onde entra a "indústria turística" composta de transportes, alojamento, alimentação, centros de recreio, comércio e todos os serviços complementares.

Beni (2001, p. 46) propõe o "Sistema de Turismo - SISTUR”, que é considerado um sistema aberto, e que organiza o turismo em três grandes conjuntos: o das Relações Ambientais, o da Organização Estrutural e o das Ações Operacionais, cada um deles com suas funções que atuam interagindo no sistema total, cabe a ambos, poder público e iniciativa privada, a tarefa de planejar a atividade turística. Ainda dentro da obra de Beni (2006) ele faz importante conside- 
ração sobre planejamento onde cita que o modelo de gestão adotado deverá priorizar a participação de segmentos empresariais permitindo atingir compromissos permanentes entre a iniciativa privada e o poder público, por meio de instrumentos que conduzem, entre outros à gestão compartilhada; participação mutua em custos; identificação de todos os agentes institucionais, sociais, e empresariais participantes do processo de desenvolvimento sustentável do turismo na região (BENI, 2006 p.96)

Ascanio (1998, p. 33) também propõe um modelo conceitual para análise do Sistema Turístico, composto por três elementos: o ambiente físico e empresarial; o ambiente da política turística, e o ambiente da comunidade composto pelos turistas e pela comunidade receptiva.)

Molina (1991) representa o turismo como um sistema aberto, que está dentro de um supersistema sócio-cultural. Dentro do sistema turístico distingue a superesetrutura, a demanda e a comunidade receptora, de um lado e, do outro, os atrativos, os equipamentos e instalações e a infra-estrutura.

Independentemente do modelo de representação da atividade turística que possa ser escolhido, as câmaras de turismo, por sua estrutura e funcionamento, enquanto organizações do terceiro setor, oferecem a possibilidade de articulação entre os diferentes elementos do sistema. Estas têm um duplo papel, por um lado o de congregar os diferentes setores da iniciativa privada, hotelaria, agenciamento, alimentação, etc. para construir o consenso sobre suas necessidades e reivindicações, e por outro lado o de representar todos estes setores perante os órgãos oficiais e a comunidade.

Se, por exemplo, se for escolhido o SISTUR como esquema de representação da atividade turística, poder-se-ia dizer que uma câmara de turismo permite a articulação dos três grandes conjuntos e a dos segmentos empresariais da iniciativa pública e privada, atividade esta muito difícil de quantificar mas que pode ser objeto de estudos qualitativos, como o que se apresentará a seguir. 


\section{Os Modelos de Planejamento da Atividade Turística}

Um documento pioneiro na sistematização dos modelos é o de Getz (1986, p. 29), que realizou um estudo dos trabalhos publicados sobre planejamento do turismo de quarenta e sete diferentes autores e identificou três tipos, os modelos teóricos, os modelos de planejamento e processos de gestão, e os modelos de previsão e uma das recomendações que emanam do seu trabalho é integrar o planejamento de turismo com outras instâncias da sociedade

\footnotetext{
... Finalmente, a menção dos modelos teóricos é para lembrar aos planejadores do turismo para não agirem de forma isolada de outros tipos de planejamento, o social, o econômico e o ambiental. Existe uma tendência de pensar o planejamento do turismo como um problema isolado, definido em forma limitada que somente inclui o marketing e os serviços ao turista. A teoria e o conhecimento existentes sobre os múltiplos impactos possíveis do turismo desacreditam completamente essa tendência (GETZ, 1986, p. 31) (trad. dos autores).
}

Segundo Barretto (2002, p. 14-15), o planejamento é orientado pelos seguintes princípios: inerência (é indispensável planejar); universalidade (tenta prever todas as variáveis e conseqüências); unidade (as diversas partes do planejamento devem estar unidas de modo coerente e integrado); previsão (planejar é fazer previsões) e - o que interessa a este trabalho- o princípio da participação (deve envolver a participação de todos os níveis e setores da administração).

Barretto (2002, p. 59) ainda propõe que o planejamento turístico seja visto dentro de um critério de complexidade crescente que pode ser dividido em: Planejamento de primeiro nível eventos, excursões e viagens; Planejamento de segundo nível - transformação de cidades em núcleos turísticos, ativação de núcleos turísticos preexistentes, criação de complexos ou cidades turísticas (construção de equipamentos turísticos);e Planejamento de terceiro nível - políticas nacionais para incentivar a atividade turística no país e organizá-la, abrangendo os outros dois níveis.

De acordo com essa definição o papel da iniciativa privada estaria reservado ao primeiro nível, sendo que o segundo e terceiro nível seriam atividade exclusiva do poder público. Como será visto a seguir, uma entidade do terceiro setor, como por exemplo uma câmara de turismo, pode participar do planejamento em qualquer um dos três níveis; no primeiro convocando os 
diversos representantes da atividade privada para participar de eventos, e missões comerciais, no segundo nível, articulando o setor privado para realizar investimentos em regiões que estejam sendo desenvolvidas, e no terceiro nível atuando na criação de políticas, tendo um importante papel para influenciar na criação de leis que dizem respeito ao planejamento da atividade turística.

\section{O Papel do Setor Público e do Setor Privado no Turismo}

Na maior parte dos modelos de sistematização e planejamento de turismo, os autores concordam que o papel do setor público no mesmo é o de cuidar do planejamento, da regulamentação e do controle da atividade turística, assim como da promoção institucional, do financiamento do desenvolvimento, a definição e controle da capacitação dos recursos humanos e o fomento da atividade Beni (1990), Baptista (1997) Barretto (2007), Getz (1986), Hall (2000), Molina (1991), Ascanio (1998), Ruschmann, 1997)

Hall (2001, p. 183) destaca que são sete as funções do poder público no turismo: coordenação, planejamento, legislação e regulamentação, o governo deve incentivar e difundir o turismo e ocupar-se de oferecer programas de turismo social.

Para o caso do Brasil, Beni (2001, p. 100) recomenda que o planejamento e desenvolvimento do turismo sejam exclusividade do poder público

Ruschmann (1997, p. 101) reforça o papel do estado no planejamento:

A responsabilidade do planejamento turístico integrado, que considera todos os aspectos e fatores intervenientes da atividade, é do organismo estatal específico que, por sua origem, dispões de mais recursos financeiros, e técnicos

Beni (2001, p. 108) adaptando quadro criado por Acerenza (1985), relaciona cinco atividades principais do poder público no setor turismo. São elas: 1) facilitação; 2) desenvolvimento da infra-estrutura; 3) transporte e comunicações; 4) educação e capacitação; e 5) prestação de serviços. Somente a atividade de prestação de serviços é atribuída como responsabilidade da 
iniciativa privada ficando a as atividades de educação e capacitação a ser compartilhadas do poder público com a iniciativa privada.

Segundo este autor, o poder público, no processo de planejamento do turismo ainda teria o papel de construir um consenso entre todas as atividades sistematizadas acima

O Turismo só poderá desenvolver-se adequadamente quando lhe for dada uma estrutura institucional apropriada, governamental ou semi-governamental (BENI, 2001, p. 113).

Essas reflexões sobre o papel do poder público nas atividades do turismo se constituíram num paradigma aceito pela maioria dos países que têm desenvolvido a atividade turística durante as últimas décadas do século passado (BENI, 2001; TYLER, GUERRIER E ROBERTSON, 2000)

A Organização Mundial do Turismo apresenta um panorama histórico da participação dos governos na atividade turística, que revela que nos anos que seguiram à criação deste órgão supranacional, a liderança das atividades turísticas era do poder público que tinha a última palavra nas decisões:

No primeiro período de desenvolvimento turístico, a partir da década de 1960 aproximadamente [...] os governos desempenharam um papel pioneiro. Sua função era considerada essencial desde que eram necessários grandes investimentos para construir infraestrutura e instalações básicas para levar o turismo a determinadas regiões e fomentar o crescimento das mesmas. Naquele momento não cabia esperar que o setor privado investisse [...] (OMT, 2001, p. 10-11). (trad. dos autores)

O estudo realizado pela Organização Mundial do Turismo, Cooperación entre los Sectores Público y Privado (OMT, 2001) demonstrou uma retração por parte dos governos nos investimentos em infraestrutura e no apoio ao desenvolvimento dos serviços turísticos no período compreendido entre 1960 e 2000.

Dentro de uma política mundial de desregulamentação, os governos nacionais pouco têm feito na área de legislação para o setor turístico, salvo no que se refere aos direitos do consumidor e na defesa da cultura do patrimônio e do meio-ambiente. A maioria dos países começou a delegar o poder de decisão às autoridades regionais e locais iniciando o afastamento dos governos nacionais da área turística (TYLER, GUERRIER e ROBETSON, 2000) 
Os últimos anos do século XX, se caracterizaram por fortes restrições orçamentárias na área pública, incrementando a preocupação destes governos de como justificar o fato de estarem destinando o dinheiro do contribuinte para apoiar e promover o desenvolvimento turístico nacional em detrimento de outras necessidades prioritárias da população.(BARRETTO, 2010)

As mudanças acontecidas a nível mundial, por efeito da globalização da economia têm tirado do poder público sua força econômica e a sua disposição para realizar investimentos no desenvolvimento do turismo, precisando, portanto, aliar-se com os capitais privados, como afirma Beni(2001, p. 118). :

nenhuma instituição pública de turismo no país poderá prescindir, na atual conjuntura socioeconômica nacional e mundial da cooperação direta e eficaz da iniciativa privada."

Estas afirmações são endossadas em nível internacional por pesquisadores que vêm observando o fenômeno em outros países. McIntosh et al (2002, p. 344) afirmam que:

O governo e a sociedade civil devem interagir de forma cooperativa para o bom desenvolvimento do turismo. Pode haver conflito político quando membros do governo consideram que o setor privado deveria fazer mais por si próprio e os empresários acreditam que o governo deveria fazer mais para assisti-los (McINTOSH et al, 2002, p. 344).

Sem discordar do anterior, Hall lembra que ainda o poder decisório é do estado:

Embora as fronteiras do estado estejam se tornando cada vez mais indistintas em várias jurisdições à medida que se coloca cada vez mais ênfase na criação de parcerias público-privadas e se reduz a intervenção do governo na economia, deve-se observar que o estado ainda determina a estrutura em que ocorre a atividade pública e privada.[...] As funções do estado afetarão a política o planejamento e o desenvolvimento turístico em diferentes graus (HALL, 2001, p.183-184).

Analisando uma conjuntura pontual dentro do âmbito nacional Beni (2001, p. 118).afirma que:

surgiu recentemente um avanço no sistema de parceria em virtude da falência do estado na solução dos problemas sociais com responsabilidade e justiça. O Governo Federal vem conferindo ênfase à formação das organizações sociais. Parte-se agora, para o denominado terceiro setor, formado pelas diversas organizações da sociedade civil que, em conjunto com o setor privado e o estado, deverá pactuar um novo contrato social, com a redefinição de suas próprias responsabilidades. 
O relacionamento entre os diferentes atores da atividade turística pode ficar afetado pela indefinição dos seus papeis no desenvolvimento e operação de um destino. Assim, apesar de afirmar que o futuro do planejamento de turismo está nas diversas organizações do terceiro setor, Beni (2001, p. 48) diz que o poder público deve deter a responsabilidade de definir o tipo de turismo desenvolvido, fiscalizar e regrar para com isso exercer a responsabilidade para com os interesses coletivos e desta forma, assegurar que os benefícios dele auferidos não sejam obtidos em detrimento das necessidades sociais, culturais e ambientais.

Isto implica um processo de transição na distribuição das responsabilidades no planejamento e desenvolvimento do turismo, que exige de todas as partes um reposicionamento. Por um lado o poder público deve abrir mão de parte do exercício de liderança e definição das atividades turísticas em favor da iniciativa privada. Por outro lado, a iniciativa privada deve assumir parte dos custos, antes atribuídos ao poder público, assim como, compartilhar as tomadas de decisões com o poder público e a comunidade.

\section{O Terceiro Setor e o Turismo}

Por Terceiro Setor, entende-se o conjunto de "instituições sem fins lucrativos que, a partir do âmbito privado, perseguem propósitos de interesse público” (THOMPSON, 1997, p. 41).

A expressão foi traduzida ao português a partir do inglês Third Sector, usado nos Estados Unidos como equivalente a "organizações sem fins lucrativos" e "organizações voluntárias", que na Inglaterra são denominadas ainda com o conceito medieval charities, ou mais modernamente filantropia ou mecenato. (FERNANDES, 1997)

Denomina-se terceiro setor, em relação ao primeiro setor, que seria o Estado, e ao segundo, que é o setor das atividades lucrativas. Trata-se de um setor independente que não quer "submeter-se nem à lógica do mercado nem à lógica governamental” (CARDOSO, 1997, p. 8)

É composto de organizações sem fins lucrativos,

criadas e mantidas pela ênfase na participação voluntária, num âmbito nãogovernamental, dando continuidade às práticas tradicionais da caridade, da filantropia e do mecenato (FERNANDES, 1997, p. 27) 
Ainda há muita discussão sobre qual é o papel do Terceiro Setor mas há consenso entre os pesquisadores de que trata-se de um setor eclético (quando não qualificado de confuso) que comporta vários tipos de organizações Thompson (1997), Cardoso (1997), Fernandes (1997) Montaño (2002), Ciconello 2004). No Brasil, seus limites estão regidos pela Lei 9.970/99, que rege sobre as Organizações da Sociedade Civil de Interesse Público (OSCIP).

Como observa Paes (1999, p. 45).definindo as fronteiras entre os setores tradicionais para justificar o surgimento das organizações do Terceiro Setor.

\footnotetext{
A idéia é que nele se situem organizações privadas com adjetivos públicos, ocupando pelo menos em tese uma posição intermediária que lhes permita prestar serviços de interesse social sem as limitações do estado, nem sempre evitáveis, e as ambições do Mercado, muitas vezes inaceitáveis.
}

Embora desde a época da Colônia houve organizações filantrópicas, como por exemplo as Santas Casas da Misericórdia, ou a Beneficência Portuguesa na área da saúde, e depois foram criadas organizações assistenciais na primeira presidência de Getúlio Vargas (1930-1945) as primeiras organizações do Terceiro Setor a terem visibilidade no Brasil foram as ONGs (Organizações Não Governamentais) que surgem, na América Latina entre 1960 e 1970 a partir de iniciativas internacionais para promover o desenvolvimento do terceiro mundo (Fernandes, 1997) e passam depois a ser forças de resistência aos governos militares instalados no continente, tentando dar voz aos excluídos, fazendo política de uma forma diferente da tradicional, junto aos movimentos sociais emergentes (direitos humanos, mulheres, ecologia e outros) (THOMPSON, 1997). No Brasil

A denominação ONG tem sua origem na Europa e deve-se ao sistema de representação nas Nações Unidas, que passaram a designar Organizações Não Governamentais aquelas organizações internacionais que, embora não representassem governos tinham importância suficiente para ter um assento na ONU-Organização das Nações Unidas. (FERNANDES, 1997). No Brasil já nasceram atreladas a projetos de cooperação internacional, como instituições progresistas para a "consolidação da democracia (COUTINHO, 2004) 
A partir da década de 1980, com os processos de redemocratização do continente, configuram-se muitos blocos institucionais dentro da sociedade civil destinados à afirmação da cidadania; surge o conceito de OSCs (organizações da sociedade civil) (FERNANDES, 1997), que inclui tanto as organizações de caridade e beneficência tradicionais (filantrópicas), as ONGs, as organizações para defesa de mulheres, negros, povos indígenas, meio ambiente, promoção de esporte, de cultura ou lazer, trabalho voluntário e filantropia empresarial (CARDOSO, 1997, p. 8).

Juntos, estes blocos, com vários pontos em comum, mas também com grandes diferenças e tensões entre eles, receberão o nome de Terceiro Setor, que teria como escopo inicial propiciar "o encontro entre a lógica governamental, marcada pela permanência e universalidade das políticas e a lógica da sociedade civil, marcada pela defesa de interesses específicos e experimentação de formas inovadoras de ação" (CARDOSO, 1997, p. 8)

Com a consolidação do neoliberalismo após a queda do muro de Berlim em 1989 o papel das organizações do Terceiro Setor passa a ser menos de contestação, e mais de empresas eficientes para oferecer serviços e aliviar o papel do Estado (THOMPSON, 1997), cujo papel e situação geram controvérsias.

Para Thompson (1997, p. 42), o estado é um “conglomerado de instituições, muitas vezes sobrepostas sem nenhuma lógica, com interesses diversos e com uma definição ambígua com relação aos seus espaços de atuação" e as ONGs passam a ocupar os espaços em que o estado se omite.

Já para intelectuais como Petras (1996) a ineficiência do Estado não passa de um discurso. O Estado tem sido sempre o único a zelar pelos pobres e, se é ineficiente, deve-se à pressão dos interesses privados, e as ONGs atendem somente os setores que interessam ao capital, dando soluções paliativas que contribuem com a despolitização da sociedade e que acabam pactuando com o capitalismo.

Também nos últimos anos têm surgido críticas à vinculação do mundo dos negócios com o Terceiro Setor. Para Ciconello (2004, p. 54), que analisa a questão a partir da legislação, existe uma espécie de apropriação do conceito em benefício das empresas que leva a distorções, 
entre elas a introdução de práticas de mercado nocivas à área social e à idéia de que as entidades do terceiro setor têm uma natural vocação pública o que não é assim.

A diversidade de entidades que atuam é uma das características do terceiro setor: desde organizações religiosas e laicas, passando por políticas e apolíticas até nacionais e internacionais. Estão incluídas no Terceiro Setor tanto instituições que doam dinheiro quanto instituições que recebem dinheiro (FERNANDES, 1997; SALAMON, 1997). Para Thompson (1997, p. 45) o Terceiro Setor é um "campo onde se produz um choque de valores e tendências, dinâmico e mutável". Este ecletismo tem levado a questionar se então se justifica a sua definição com um mesmo conceito, ao que Fernandes (1997) responde que sim desde que, embora sejam instituições por vezes até divergentes, todas tem em comum fazer contraponto tanto às ações de governo quanto às do mercado, projetar uma visão integradora da vida pública e a valorizar iniciativas de participação e voluntariado.

Outros pesquisadores, no entanto, como Carrion (2000) entendem que há uma grande confusão conceitual. A Associação Brasileira de Organizações Não Governamentais que diz reunir "as mais tradicionais associações que atuam na promoção de direitos da cidadania e de apoio a movimentos populares" (www.abong.br) agrupa Sociedades Civis Não Lucrativas, as Associações, as Entidades Filantrópicas e Beneficentes, ou de Caridade, as Fundações, e as Organizações Não-Governamentais. Dentro destas, há igrejas evangélicas, hospitais, universidades e até colégios privados que visam lucro. "Ou seja, um lote de organizações, entre as quais, algumas desenvolvem atividades que pouco, ou nada, agregam para o equacionamento dos problemas sociais" (CARRION, 2000, p. 239)

As entidades filantrópicas se reúnem em torno da Rede Brasileira de Entidades Assistenciais Filantrópicas (www.terceirosetor.org.br) e as fundações e institutos vinculados a empresas se reúnem em torno do Grupo de Institutos, Fundações e Empresas (www.gife.org.br).

O papel das fundações é ainda mais discutido, já que, também conforme Carrion (ibidem) há grandes empresas com finalidade lucrativa que adotam esta forma jurídica para obter benefícios fiscais ou repasse de dinheiro público. 
Independentemente das referidas discussões, sobre se o Estado é ou não eficiente e sobre se as ONGs são mais um instrumento a serviço do capitalismo, o Terceiro Setor no Brasil vêm desempenhando um papel importante já desde a década de 1990 em que já empregavam mais de um milhão de pessoas (FERNANDES, 1997). Dados atualizados publicados em julho de 2010 pelo Instituto de Pesquisa Econômica Aplicada - IPEA, órgão vinculado ao Ministério do Planejamento informam que o Terceiro Setor tem participação de 1,5\% no PIB nacional, movimenta anualmente cerca de R 12 bilhões, emprega 1,2 milhão de pessoas e atrai ao redor de 1,5 milhão de voluntários. (IPEA, 2010).

Segundo os últimos dados disponíveis (ABONG, 2010), o número total de organizações, independentemente da conceituação adotada pelos diferentes autores, estão expressas pelo conceito de Fundações Privadas e Associações sem Fins Lucrativos (FASFIL), baseada no Cadastro Central das Empresas (CEMPRE) do IBGE, sendo em número aproximado de 276.000.

Pareceria que continuar pensando de forma dicotómica, criticando ou exaltando o s setores público e privado, a partir de posturas ideológicas não leva a melhorar a sociedade. É preciso pensar formas de avançar e neste sentido compartilha-se do pensamento de Gouvea (1999, p. 59-66) quando afirma que:

\begin{abstract}
É condenável essa tendência que se verifica nos dias de hoje de contrapor as virtudes do mercado aos vícios do estado. É importante o aperfeiçoamento dos mecanismos de intervenção do estado para que o mercado possa funcionar de maneira mais eficiente e em benefício de um projeto coletivo. É necessário que sejam superados os entraves ligados à dicotomia estado-mercado como forma de se buscar um novo padrão de gestão pública, cuja capacidade de execução esteja em consonância com a dinâmica dos interesses sociais
\end{abstract}

É preciso ver a dinâmica da sociedade, de acordo com Habermas (1984, p. 170:

$\mathrm{Na}$ área de Turismo, como já expressado anteriormente, a maioria dos países começou a delegar o poder de decisão às autoridades regionais e locais iniciando o afastamento dos governos nacionais da área. Se, de um modo geral, o Estado demonstra uma grande ineficácia em aten- 
der às demandas da sociedade (no dizer de Andrade (1997, p. 75) no final do século XX "O Estado [...] encolhe-se encabulado" ) que dizer das necessidades de um setor que não é prioritário.

As organizações do Terceiro Setor, no caso específico do turismo, podem tomar a forma de Câmara de Turismo ou um Convention \& Visitors Bureau. Todas estas organizações têm em comum o fato de não terem fins lucrativos, terem independência administrativa e gestão mista.

A Secretaria de Turismo do México - SECTUR em parceria com a OMT, na sua publicação "Desarrollo y Comercialização de Productos Turísticos" recomenda, como uma maneira de enfrentar os desafios do futuro do turismo, a criação de Destination Management Organizations - DMO ou Organizações de Gestão de Destino como a ferramenta organizacional encarregada do desenvolvimento global do produto turístico e do marketing do destino. (SECTUROMT, 1998, p. 55-58).

Uma iniciativa demonstrativa desta situação pode se encontrar na configuração da Câmara de Promoção Turística da Cingapura (STPB Singapore Touris Promotion Board).

(...) foi criada em 1964 como a organização turística nacional incumbida de desenvolver a indústria turística do país. Paralelamente às suas funções principais de marketing e de planejamento turístico, a Câmara atua como agente do governo em um amplo leque de assuntos relacionados ao turismo (KAHN, 2001, p. 106)

No entanto, até agora os âmbitos de cooperação entre o estado e a iniciativa privada no setor de turismo, têm sido quase exclusivamente nas áreas de promoção e marketing (OMT 2001, p. 17)

Há Câmaras de Turismo de muitos dos países da América Latina, com diferentes formatos. No Equador seu funcionamento é definido por uma lei que criou uma Câmara para cada província (estado). Argentina, Uruguai, Chile, Peru, Colômbia, Venezuela e Panamá têm as suas câmaras criadas como organizações privadas de interesse público sem fins lucrativos fazendo parte de uma estrutura federativa de câmaras municipais, provinciais e de uma câmara nacional que as reúne. 
No Brasil existem somente dois exemplos em nível estadual. A Câmara e o Fórum para o Turismo Sustentável do Paraná.

A Câmara de Rio Grande do Sul, pioneira no país, foi constituída em 1989 como uma sociedade civil sem fins lucrativos com o objetivo de promover o turismo receptivo do estado. É formada por representantes das associações de classe e empresariais do setor turístico do estado contando também com a participação dos cursos superiores de turismo e hotelaria, a Secretaria de Estado do Turismo e secretarias municipais de diversas comunidades.

O estado do Paraná, em 2001 criou o Fórum para o Turismo Sustentável do Paraná com as mesmas características formais da Câmara. Até o momento da redação do presente artigo não foi achada informação sobre novas iniciativas neste aspecto.

Em nível municipal, são várias as cidades brasileiras que criaram escritórios -que optaram por denominar com o anglicismo Conventions and Visitors Bureaus- entidades sem fins lucrativos, usualmente configuradas como fundações, para atender a promoção de suas cidades como destino de feiras e congressos. A totalidade deles responde à configuração das Organizações do Terceiro Setor, atuando como ponto de encontro entre o setor público e privado que participam como mantenedores em forma igualitária.

Em nível nacional, a última ação neste sentido ocorreu em 2004, quando , a Confederação Nacional do Comercio - CNC, criou a Câmara Empresarial do Turismo com abrangência nacional e integrada pelas principais entidades representativas do empresariado turístico.

\section{O Caso da Câmara de Turismo do Rio Grande do Sul}

A Câmara de Turismo de Rio Grande do Sul foi pioneira no Brasil como entidade do terceiro setor, configurada como uma fundação, focada no desenvolvimento do turismo receptivo desse Estado. Quando da sua criação e funcionamento estava integrada por representantes de diversas atividades da iniciativa privada do turismo, assim como apoiada por outras entidades relacionadas indiretamente a esta atividade como por exemplo a FARSUL -Federação da Agricultura do Estado do Rio Grande do Sul. 
Os integrantes das entidades relacionadas ao setor turístico criaram, em 1989, a Câmara, buscando, através da união destas organizações, estabelecer ações conjuntas no intuito de construir um objetivo comum que trouxesse retorno mercadológico a todo o trade turístico do Estado.

Conforme relatado pelos entrevistados, as ações da Câmara sensibilizaram o poder público obtendo como resultado a inclusão de artigo na Constituição do Estado, que trata especificamente do turismo como atividade de interesse público.

Quanto às razões que motivaram à criação da Câmara, o poder público do Estado do Rio Grande do Sul abriu mão de seu papel na atividade turística desativando a Secretaria de Turismo. Isto motivou a iniciativa privada a iniciar reuniões, em 1988, para procurar alternativas que permitissem fortalecer a atividade turística no Estado.

Os entrevistados coincidiram em afirmar que a motivação principal para a criação da Câmara foi a melhor solução para resolver ausência do Poder Público na atividade turística do Estado. Assim mesmo afirmam que outras das motivações foram: a necessidade de "trabalhar juntos", a necessidade de contar com uma estrutura operacional que permitisse desenvolver projetos comuns e a necessidade de ter uma interlocução representativa com os diferentes níveis governamentais e que o foco desta nova entidade seria o desenvolvimento do turismo receptivo do Estado.

Um elemento interessante das respostas dos entrevistados pertencentes aos grupos externos à administração da Câmara é que reconhecem que os objetivos e motivadores iniciais de seu funcionamento foram e são até hoje pertinentes, mesmo na opinião daqueles entrevistados que na época da fundação não participavam ainda da atividade turística ou não ocupavam cargos no setor.

Isto reafirma que a necessidade de uma entidade como a Câmara continua vigente mesmo com as alterações ocorridas no cenário turístico do Estado já que em 1995 foi reativada a Secretaria de Turismo e nos últimos anos foram criados três escritórios de convenções, nas cidades de Porto Alegre, Gramado e Pelotas. 
Existem divergências entre os entrevistados3 sobre qual foi o modelo que serviu de inspiração para a instituição da Câmara , mas os fundadores que responderam a esta pergunta disseram que os modelos de referencia foram as câmaras existentes em vários países latino-americanos, especialmente Argentina e Uruguai, entidades estas com as quais eles já tinham contato em congressos e férias do setor turístico especialmente o Congresso da COTAL - Confederação de Organizações Turísticas da América Latina da qual dois empresários gaúchos ocuparam a sua presidência sendo um deles o Economista Loris Isatto que exerceu por duas vezes a presidência da Câmara.

[...] sabíamos da existência de uma instituição no Paraná, que tinha uma finalidade similar àquela que nos propúnhamos a criar aqui. E também no Uruguai e também na Argentina buscou-se subsídios. Acho que no fim acabou sendo uma composição de modelos" [..] (Representante de entidade universitária e fundadora)

No que diz respeito aos principais projetos de turismo onde a Câmara participou, foi obtida, nas entrevistas uma grande diversidade de respostas. Por exemplo, no caso dos ex-presidentes, nem todos lembravam dos diversos projetos nos quais a Câmara teve participação efetiva.

Estas atividades podem ser agrupadas em ações de participação legislativa representando o setor turístico na redação da Constituição Nacional de 1988 e da Constituição Estadual de 1989, também participação no Conselho Nacional do Turismo, coordenando o setor privado nas RET- Reuniões Especializadas de Turismo do Mercosul e da criação do PRODETURSUL - Programa de Desenvolvimento do Turismo da Região Sul.

No âmbito internacional a Câmara se afilia a OMT em 1997 e no ano 2000 é eleita para ocupar uma vice-presidência do seu Conselho Empresarial do Turismo.

O papel da Câmara no desenvolvimento do turismo receptivo do Estado se manifesta no apoio a criação dos roteiros: Rota Romântica, Rota Internacional das Missões Jesuíticas (FUNMISSÕES), Rota da Uva e do Vinho (ATUASERRA) entre outros.

3 Cabe esclarecer que os representantes do poder público não responderam esta pergunta porque os entrevistados na época da criação da Câmara não exerciam nem cargo público nem estavam vinculados à atividade turística. 
Mas a realização de missões comerciais com empresários à cidades tradicionalmente emissivas do Brasil e do Mercosul acabou sendo a atividade mais lembrada pela maioria dos entrevistados.

Tudo isto vêm ao encontro dos aspectos que, enfatiza Kotler (1978, p. 76), devam ser seguidos por entidades não governamentais e não lucrativas na busca de seus objetivos de ampliação mercadológica.

Segundo Kotler (1995, pág.20):

\begin{abstract}
...Esse grupo de planejamento validará a importância da cooperação entre o setor público e privado, e a necessidade de envolver todos os contribuintes na elaboração do futuro de um local. Ele tem três obrigações: em primeiro lugar, deve definir e diagnosticar as condições da comunidade, seus principais problemas e suas causas. Como segunda função, deve elaborar uma estratégia para solucionar a longo prazo os problemas da comunidade, baseando-se em avaliações realistas de seus valores, recursos e oportunidades. E, por último, deve desenvolver um plano de ação a longo prazo, envolvendo várias etapas intermediárias de investimento e transformação.
\end{abstract}

O mesmo Kotler, junto com Haider e Rein (1995, p. 137), coloca que a região que busca efetuar seu marketing turístico, deve decidir que tipo de turista deseja. Neste aspecto a Câmara e seus associados optaram por direcionar a maior parte de seus esforços na captação de turistas provenientes da Argentina, Uruguai e Chile.

Contudo, na busca de um maior incremento e participação do turismo interno, também foram desenvolvidas atividades em outros estados do Brasil. Estas ações foram efetuadas tendo em vista suas potencialidades, que atraem o turista proveniente do norte e nordeste do próprio país, uma vez que as características climáticas e geográficas do estado do Rio Grande do Sul, pelo contraste, diferem de suas regiões de origem.

Com este intuito, como já ressaltado, os integrantes da Câmara e seus associados, organizaram encontros de negócios nos países e regiões citadas, efetuando contato com agentes de viagens e operadoras, além de participarem de feiras e eventos ligados à área de turismo, na busca de promover o estado do Rio Grande do Sul demonstrando o potencial de zona turística que a região possui. 
Outro aspecto que deve ser detectado no marketing de destino desenvolvido pela Câmara é o trabalho institucional desenvolvido junto a outras entidades ou organizações que atuam na área turística. Este aspecto pode ser comprovado pela participação que a Câmara teve no Conselho Empresarial da OMT- Organização Mundial do Turismo, colocando as entidades associadas, a Câmara e o estado do Rio Grande do Sul em evidência junto a grandes empresas e organizações do trade turístico mundial. Também por intermédio da Câmara, foi realizado em 2000 o primeiro Seminário de Contas Satélite de Turismo no intuito de sensibilizar autoridades e iniciativa privada para a implantação desta metodologia de medição do impacto econômico do turismo, idealizada pela OMT.

Além disso, a coordenação e o auxilio na implantação do Porto Alegre Convention \& Visitors Bureau, tem permitido a captação e execução de diversos grandes eventos, das mais distintas áreas, uma vez que a localização privilegiada da cidade coloca-a como ponto central para o deslocamento de participantes provenientes das capitais do Uruguai, Chile, Argentina e Paraguai e de cidades como São Paulo, Rio de Janeiro, Curitiba e Florianópolis, com as quais está conectada por malha aérea satisfatória.

As respostas obtidas a respeito do relacionamento entre a Câmara e as instituições associadas evidenciam algum dos que poderiam ser os principais empecilhos para que a Câmara seja eficaz na sua função: a resistência dos diversos interlocutores em reconhecer a liderança que esta entidade necessariamente tem que exercer, para efetivar seu papel de representação das entidades do setor turístico.

Para entender esta resistência é necessário entender que este setor está composto por diversas entidades que representam vários setores empresariais do turismo, empresários hoteleiros, empresários da gastronomia, das agencias de turismo, etc., cujos dirigentes têm que prestar contas de suas ações em defesa do setor para seus colegas empresários e muitas vezes interpretam as atividades da Câmara como uma ameaça para sua imagem de dirigentes e para a visibilidade de sua entidade.

Também aparece nas pesquisas a menção ao não exercício da liderança por parte de alguns dos diretivos da Câmara. 
Os motivos destas situações podem ter origem em questões culturais, de formação e até comportamentais dos diferentes atores que participam, direta ou indiretamente da gestão da Câmara e poderiam ser objeto de um estudo mais aprofundado no futuro já que as implicações de um trabalho deste teor superam os objetivos do presente artigo. O depoimento abaixo transcrito, resume a questão:

“A cultura brasileira é uma cultura muito corporativa. Seja no meio empresarial, seja no meio dos trabalhadores, seja no meio das universidades, [...]. E uma Câmara para funcionar ela tem que ir além dos aspectos corporativos, então ela precisa da adesão e a adesão, o motivo principal da adesão é a confiança". (Representante do Poder Público)

A pergunta a respeito do relacionamento entre a Câmara e o poder público teve respostas similares à anterior tanto nas suas justificativas como nas implicações respeito das questões atitudinais dos atores que participam do campo de forças no qual a Câmara exerce suas funções.

Da mesma forma que acontece com os dirigentes de algumas entidades associadas, no resultado das entrevistas aparecem evidencias de resistência às atividades da Câmara por parte de políticos e funcionários das entidades públicas do turismo que se manifestas de diversas maneiras como boicote, sonegação de informação, concorrência e duplicação de atividades.

\section{Considerações Finais}

Ao estudar a historia da Câmara, observa-se que em seus 16 anos de atuação ela tem demonstrado sua capacidade de ação e sua importância em vários aspectos da atividade turística do Estado e do Brasil, que, embora não possam ser quantificados, podem ser apreciados numa abordagem histórica do desenvolvimento geral do turismo no Estado

Poderia ser considerada um modelo de gestão, que cumpre os requisitos apontados por Getz de um planejamento integrado e, como foi observado anteriormente, que pode trabalhar em diferentes níveis de planejamento.

$\mathrm{Na}$ área de estimulo e apoio ao desenvolvimento do turismo do Estado fica evidente sua atuação junto dos roteiros integrados como Rota Romântica e Rota das Missões entre outras. 
Na promoção e comercialização de produtos turísticos com a sua constante realização de missões comerciais e participação em eventos e feiras profissionais no Brasil e nos países do Cone Sul.

Na representação do setor empresarial do turismo tem realizado diversas atividades em diversos foros como nas Reuniões Especializadas de Turismo do Mercosul, no Conselho nacional de Turismo e como membro do Conselho Empresarial da OMT, entre outras. Assim como na interlocução com os governos Federal, Estadual e municipais.

Também é possível afirmar que desde a data da sua fundação, a Câmara enfrentou diversos desafios relacionados principalmente ao seu pioneirismo como entidade do terceiro setor, ingressando em um ambiente que tradicionalmente era compartilhado exclusivamente pelo poder público e pela iniciativa privada.

Esta nova situação que nem sempre foi compreendida ou apoiada efetivamente pelas entidades associadas e pelos administradores públicos e tal como pode ser percebido nas entrevistas realizadas, se evidencia que a Câmara, algumas vezes, foi considerada uma concorrente nas atividades, no prestigio e na representação, tanto pelo poder público como pelas entidades empresariais afiliadas a mesma.

Um outro aspecto que chamou a atenção do pesquisador à luz das entrevistas realizadas é a evidencia de que a maioria dos membros das entidades assume as funções de direção por motivos diferentes de sua capacidade administrativa e sua capacitação. Isto provocou uma forte dependência por parte da instituição à personalidade e caráter do dirigente.

Isto nos permite refletir sobre a necessidade de realizar outros estudos sobre as relações interpessoais nas organizações, as relações de poder, assim como as questões comportamentais dos membros das entidades para poder compreender melhor o funcionamento de este tipo de organizações e, tal vez, aportar com um possível caminho de solução para estas assimetrias.

Um último aspecto, mas nem por isso o menos importante, que não pode deixar de ser citado, é que a simples existência de um organismo como a Câmara, tem auxiliado o Estado e a pró- 
pria Secretaria de Turismo do Estado do Rio Grande do Sul a terem maior agilidade administrativa e operacional para participar em feiras e eventos nacionais e internacionais.

Nos últimos anos, a observação empírica mostra um declínio das atividades da Câmara, fato que não foi abordado neste artigo. Futuras pesquisas poderiam estudar esta etapa de forma a subsidiar organizações similares que venham a ser implantadas.

\section{Referências}

ABONG Associação Brasileira de Organizações Não Governamentais. Disponível em: http://www.abong.org.br/s/d. Acesso 25 abr 2010.

ANDRADE, Roberto P. C. de. Considerações de fim de séulo. In:In: IOSCHPE, E. et al. $3^{\circ}$. Setor. Desenvolvimiento Social Sustentado. Rio de Janeiro: Paz e Terra, 1997.pp. 73-80

ASCANIO, Alfredo. Elementos Del Turismo como Sistema. Mérida: Editorial Venezolana, 1998.

PATRUCCO, Luis Gustavo. O Terceiro Setor no Turismo: O Caso da Câmara de Turismo do Rio Grande do Sul (Bresil) Dissertação (Mestrado em Turismo) Universidade de Caxias do Sul, 2006.

BAPTISTA, Mario. Turismo. competitividade sustentável. Lisboa:Verbo, 1997.

BARRETTO, Margarita. Manual de Iniciação ao Estudo do Turismo. Campinas: Papirus, (19. ed) 2010 .

BARRETTO, Margarita. Planejamento responsável do turismo. Campinas: Papirus, 2005.

BENI, Mario. Analise Estrutural do Turismo. São Paulo: Senac. 2001.

BRASIL: Constituição da República Federativa do Brasil-1988. Disponível em https://www.planalto.gov.br. Acesso em 12 out. 2004.

CARDOSO, Ruth. Fortalecimento da Sociedade Civil. In: IOSCHPE, E. et al. $3^{\circ}$. Setor. Desenvolvimiento Social Sustentado. Rio de Janeiro: Paz e Terra, 1997. pp. 7-12

CARRION, Rosinha M. Organizações privadas sem fins lucrativos: a participação do mercado no terceiro setor. Tempo Social. Vol 12, n. 2, 2000. pp. 237-255. Disponível em http://www.scielo.br/pdf/ts/v12n2/v12n2a15.pdf

CAYÓN COSTA, Magda. Análisis comparativo de la eficiencia de la empresa pública respecto la empresa privada. Aplicado a empresas hoteleras en España. Tesis de Doctorado. 
Universidad Autónoma de Barcelona. Dpto de Economiía de la Empresa. Barcelona. 2007. Disponível em http://www.tdcat.cesca.es/TESIS_UAB/AVAILABLE/TDX-1031107155511/mcc1de1.pdf

CICONELLO, Alexandre. O conceito legal de público no Terceiro Setor. In: SZAZI, Eduardo (org) Terceiro Setor. Temas polêmicos. São Paulo:Peirópolis, 2004.

DOIRON, Ashley. Tourism Development and the third sector. A case study on Dawson City, Yukon. Thesis. Master of Arts. Department of Anthropology. Concordia University. MOntreal, Quebec, Canada, 2001.

DREHER, Marialva T; GORNI, Patrícia M. Estratégias intersetoriais para o desenvolvimento do turismo de natureza: desafios e perspectivas. Turismo em Análise. Vol 21 n. 3. Dezembro, 2010. pp. 567-593.

FERNANDES, Rubem C. O que é o Terceiro Setor? In: IOSCHPE, E. et al. $3^{\circ}$. Setor. Desenvolvimiento Social Sustentado. Rio de Janeiro: Paz e Terra, 1997. pp. 25-34

FREIRE-MEDEIROS, Bianca. Gringo na Laje.produção, circulação e consumo da favela turística. Rio de Janeiro: Editora FGV. (Coleção FGV de bolso. Série Turismo), 2009.

GORNI, Patrícia M; DREHER, Marialva T; MACHADO, Denise d P. N. Parceria e cooperação inter setorial em uma organização do terceiro setor: o caso de Balneário Camboriu com Vida Convention \& Visitors Bureau. Turismo Visão e Ação. Vol 11, n. 2, 2009. pp. 263-279, Maio-Agosto.

GOUVÊA, Ronaldo Guimarães. Politicas públicas, governabilidade e globalização. Revista do Legislativo ${ }^{\circ} 25$. Belo Horizonte, 1999.

HABERMAS, Jürgen. Mudança Estrutural da Esfera Pública. Rio de Janeiro: Edições Tempo Universitário, 1984.

HALL, C. Michael. Tourism Planning. Policies, Processes and Relationships. England: Pearson Education Ltd. 2000.

HALL, Michael. A Tomada de decisão política e o planejamento centralizado. Darling harbour, Sydney. In: TYLER, Duncan.GUERRICA, Yvonne. e ROBERTSON, Martin (orgs.). Gestão de Turismo Municipal. Teoria e Prática do Planejamento turístico nos centros urbanos. São Paulo: Futura. 2000.

IBGE. As Instituições Privadas e Associações sem Fins Lucrativos no Brasil. Rio de Janeiro: Gerência do Cadastro Central de Empresas, 2002. in http://www.ibge.gov.br/home/estatistica/economia/fasfil/default.htm. S/D

IPEA. Sensor revisa previsão de crescimento do PIB para cima. Disponível em: http://www.ipea.gov.br/portal/index.php?option=com_content\&view=article\&id=1995:sensor 
-revisa-previsao-de-crescimento-do-pib-para-cima\&catid=3:dimac\&Itemid=3. 27/07/2010. Acesso 25 abr. 2011.

KHAN, Habibullah. A explosão do turismo - Decisões políticas em Cingapura. In: TYLER, Duncan.GUERRIER, Yvonne. e ROBERTSON, Martin. (orgs.). Gestão de Turismo Municipal: teoria e prática do planejamento turístico nos centros urbanos. São Paulo: Futura, 2000.

KOTLER, Philip. Marketing para organizações que não visam lucro. São Paulo: Atlas, 1978.

KOTLER, Philip; REIN, Irving; HAIDER, Donald H. Marketing público: como atrair investimentos, empresas e turismo para cidades, regiões, estados e países. São Paulo: Makron Books. 1995.

LAVILLE, Christian e DIONNE, Jean. A construção do saber. Manual de Metodología da pesquisa em ciências humanas. Belo Horizonte/Porto Alegre:Editora UFMG/Artmed, 1997.

MARCONI, Marina de A. e LAKATOS, Eva. 1982. Técnicas de Pesquisa. São Paulo:Atlas

MATTOS, Solange M. S. N; DRUMMOND, José A. O Terceiro Setor como executor de Políticas Públicas. Ongs ambientalistas na Baia de Guanabara. (1990-2001). Revista de de Sociologia $e$ Política, n. 24, 2005. pp. 177-192. Disponível em http://redalyc.uaemex.mx/pdf/238/23802412.pdf

MCINTOSH, Robert W.; GOELDNER, Charles R.; RICHIE, J.R. Brent. Turismo: princípios, práticas e filosofias. Porto Alegre: Bookman, 8ed. 2002.

MOLINA, Sergio. Conceptualización del Turismo. Mexico: Limusa/Grupo Noriega Ed. 1991.

OMT - ORGANIZAÇÃO MUNDIAL DO TURISMO./CEOMT - Consejo Empresarial de la Organización Mundial de Turismo. Cooperación Entre los Sectores Público y Privado. Madrid: Ed. OMT, 2001.

PAES, José Eduardo Sabo. Fundações e Entidade de Interesse Social. Brasília: Ed. Brasília Jurídica. 1999.

PEREIRA, Cássio A. S. Organizações do terceiro setor no desenvolvimento das políticas de turismo e de lazer. Turismo em Análise, maio, v. 16, n. 1, 2005. p. 68-84.

PERONI, Vera M. V; OLIVEIRA, Regina T. C.; FERNANDES, Maria D. E. Estado e Terceiro Setor: As novas relações entre o público e o privado. Educação e Sociedade, vol. 30, n. 108, 2009. p. 761-778, Outubro. Disponível em http://www.cedes.unicamp.br

PETRAS, James. El postmarxismo rampante. Uma crítica a los intelectuales y las ONG. (Publicado orignialmente na revista Excelsior em 1996) La Fogata Digital. Colección de documentos de James Petras. Disponível em http://www.lafogata.org/recopilacion/petras2.htm 
RABINOVICI, Andréa.; FERREIRA, Lúcia da C. Organizações não governamentais e Turismo Sustentável. Participação e conflitos. IV Encontro Nacional da Anppas Julho. Brasília. DF, 2008.

RICHARDSON, Roberto Jarry. Pesquisa social: métodos e técnicas. 3. ed. São Paulo: Atlas, 2007.

RIO GRANDE DO SUL - Constituição do Estado do Rio Grande do Sul, disponível em http://www.al.rs.gov.br. s/d. Acesso em 12 out. 2004.

RUSCHMANN, Doris van de Meene. Turismo e planejamento sustentável: a proteção do meio ambiente. Campinas. São Paulo: Papirus, (Coleção Turismo). 1997.

SALAMON, Lester. Estratégias para o desenvolvimento do terceiro setor. In: IOSCHPE, E. et al. $3^{\circ}$. Setor. Desenvolvmiento Social Sustentado. Rio de Janeiro: Paz e Terra, 1997. pp. 89111.

SECTUR - OMT. Manual de Desarrollo y Comercialización de Productos Turísticos. México-DF: SECTUR, 1998.

THOMPSON, Andrés A. Do compromisso à eficiência,Os caminhos do Terceiro Setor na América Latina. In: IOSCHPE, E. et al. $3^{\circ}$. Setor. Desenvolvmiento Social Sustentado. Rio de Janeiro: Paz e Terra, 1997. pp. 41-48.

THOMPSON, Paul. The voice of the past. Oral History. Oxford: Oxford University Press, 1978.

TYLER, Duncan; GUERRIER, Yvonne; ROBERTSON, Martin. Gestão de Turismo Municipal. Teoria e prática de planejamento turístico nos centros urbanos. São Paulo: Futura, 2001.

WÖHLKE, Marina. A atuação do terceiro setor no turismo alternativo. Análise do desempenho das ONGS ambientalistas no Brasil. Dissertação. Mestrado em Turismo e Hotelaria. Universidade do Vale do Itajai. 2005.

Sites consultados

PARADORES. http://www.parador.es/castellano/conocenos/mirando.jsp s/d. Acesso em 18 maio 2010.

\section{Recebido em: 16/06/2011 ( $1^{\text {a }}$ versão) 25/04/2011 (2 ${ }^{\text {a }}$ versão)}

Aprovado em: 25/04/2011 